\title{
A assimetria
}

tecnológica e a

nova economia

na sociedade

global da

informação

\section{Introdução: a sociedade pós- industrial e a era digital}

\section{RESUMO}

O texto pretende oferecer uma análise dos quesitos relacionados à sociedade global da informação no que diz respeito às gradações econômicas entre os países, onde a tecnologia assume a condição de parâmetro de riqueza. Neste sentido, apresentamos um breve panorama da geopolítica mundial das tecnologias da informação - baseado nos relatórios do Fórum Econômico Mundial e da Cúpula Mundial da Sociedade da Informação - ao mesmo tempo em que avaliamos a condição da economia frente ao novo contexto sóciotecnológico.

\section{ABSTRACT}

This text analyses the New Global Information Society thru economic indicators which reveal de assymetric relation between the technologies of poor and rich countries, based upen reports of the World Economic Form and the World Summit of Information Society.

\section{PALAVRAS-CHAVE (KEY WORDS)}

- Sociedade da Informação (Information Society)

- Nova economia (New economy)

- Cibercultura (Cyberculture)

Messias Guimarães Bandeira FTC - Bahia

A subordinação do Estado-nação contemporâneo ao processo de internacionalização dos mercados e das economias vai facilitar a conformação de uma sociedade mundializada na segunda metade do século XX. O surgimento da Comunicação Mediada por Computadores (CMC), em 1969, juntamente com o desenvolvimento da microinformática na década de 1970, imprimiu transformações significativas na produção e distribuição do conhecimento humano. No pequeno histórico do processamento automático da informação e da comunicação em rede, veremos que as inúmeras tecnologias daí provenientes irão repercutir em diversos aspectos da vida social, o que imputou às sociedades atuais a designação geral de "Sociedade Tecnológica". Neste contexto, os processos comunicacionais, favorecidos pela mediação tecnológica, irão se apresentar enquanto elementos estruturantes da chamada "era planetária".

A crise da bolsa de Nova Iorque, em 1929, foi, provavelmente, o mais significativo prenúncio do processo de globalização que caracteriza as sociedades atuais, demonstrando a dependência econômica entre os países e os efeitos em cadeia das variações dos mercados globais. A quebra da bolsa repercutiu em vários países, gerando um descontrole monetário, apresentando graves efeitos como o desemprego e a inflação. Já a agudez dos embates delimitados pela Segunda Guerra Mundial "internacionalizava", de maneira única na histó- 
ria da humanidade, os interesses e conflitos entre os países. O período do pós-guerra verá um rápido avanço dos meios de comunicação de massa, bem como do desenvolvimento científico e tecnológico. $\mathrm{O}$ fim da guerra também será marcado pela oposição entre os blocos capitalista e comunista, dando origem à Guerra Fria, onde os Estados Unidos e a União Soviética polarizavam as ameaças e as intenções de políticas totalizantes. A disputa se estendia aos âmbitos científico e tecnológico, do desenvolvimento de armas nucleares aos requintes da corrida espacial.

Por sua vez, o período entendido como pós-industrial ${ }^{1}$ será identificado por vários autores como uma nova etapa das sociedades em função das rupturas históricas, das mudanças de uma economia baseada em produtos para uma economia de serviços, da celeridade dos avanços tecnológicos - sobretudo da informatização. Alain Touraine vai se referir, em 1969, à sociedade pós-industrial enquanto uma "sociedade programada" em função dos modos de produção e organização econômica, onde a oposição capital-trabalho será superada por novas formas de dominação soci$\mathrm{al}^{2}$. Em 1973, Daniel Bell publica o livro The Coming of Post-Industrial Society ${ }^{3}$, onde o conceito de sociedade pós-industrial é desdobrado em paralelo à noção do fim da ideologia, tese que ganhou corpo na década de 1960. Para o autor, as origens destas transformações são, sobretudo, de ordem científica e tecnológica, o que não estará distante de discursos posteriores ao seu.

Para Lyotard (1986, p. 3) a era pós-industrial tem início nos últimos anos da década de 1950, período marcado pelo final da reconstrução da Europa. Assim, se a era pós-industrial possui seu viés econômico e tecnológico, será a noção de pós-modernidade que irá circunscrever as mudanças na esfera da cultura e da própria ciência. Por seu lado, a pretensão universalizante da ciência sofrerá constantes questionamentos com as novas formas de circulação do conhecimento. Se o Iluminismo e a moderni- dade lhe rendiam uma devoção quase que divina, a sociedade contemporânea vai transformá-la em mais um conjunto de mensagens passível de organização, distribuição e consumo. Esta mercantilização do saber, submetida à informatização das sociedades, vai cristalizar uma nova disputa pelo domínio da informação, como observa Lyotard:

Do mesmo modo que os Estados-nações se bateram para dominar territórios, e com isso dominar o acesso e a exploração das matérias-primas e da mão-de-obra barata, é concebível que eles se batam no futuro para dominar as informações (Lyotard, 1986, p. 5)

Desta maneira, a propriedade da informação é um elemento de constantes disputas entre os países, grupos sociais ou organizações empresariais, caracterizando, também, o entorno da comunicação contemporânea (se entendermos esta do ponto de vista do fluxo informacional). O domínio da informação será fundamental para a composição da riqueza na sociedade contemporânea, embora seu processamento esteja aquém da capacidade dos indivíduos, continuamente submetidos à rapidez e ao excesso de informações. A instantaneidade da comunicação, a flexibilidade dos fluxos de informação e a sua descentralização vão caracterizar, de formas distinta e singular, as redes globais de comunicação. $\mathrm{O}$ ambiente digital será o espaço de profundas modificações para as sociedades, como registram Breton e Proulx:

Uma das grandes mudanças, talvez a mais importante desde a Antiguidade, que afeta do interior as técnicas de comunicação, é o crescimento do paradigma digital, tal como a ideologia moderna da comunicação o tornou possível (Breton e Proulx, 2002, p. 99).

A Internet irá aglutinar, então, o conjunto maior da comunicação mediada por computadores, apresentando-se enquanto um intervalo imaterial de processos huma- 
nos reunidos por computadores. O ambiente digital irá delimitar um novo panorama para a comunicação, a cultura, a economia e a política. Contudo, a inscrição neste ambiente vai depender da apropriação tecnológica e da capacidade de produção e processamento da informação pelas sociedades, como veremos a seguir.

\section{A geopolítica do capitalismo informacional e a sociedade global da informação}

A condição da comunicação na sociedade contemporânea tem demonstrado uma maior complexidade à medida que se embute à informática. A parcela mínima da informação, o bit, será o ponto de partida para a mensuração de riquezas e negociação de dados. A unidade binária vai definir as relações econômicas e políticas, servindo de referência no mundo digital para a institucionalização do poder. Outro fator de vital importância para as relações entre os países será o grau de conectividade atingido por cada sociedade. Sob esta perspectiva, a apropriação da Tecnologia da Informação (TI) pode redesenhar o mapa da Sociedade Global da Informação.

Concebida por vários estudiosos há mais de quatro décadas — entre eles, o já citado Daniel Bell - , a noção de Sociedade de Informação sofre, hoje, pelo excesso do seu uso e pela descaracterização do conceito. Aliás, Miège (2000, p. 112) vai se referir à "impensável sociedade da informação" em função da imprecisão do termo e da insustentabilidade de seus propósitos (o êxito dos setores de serviços, a independência destes em relação às atividades industriais, a desmaterialização da sociedade etc.). Entretanto, o termo Sociedade da Informação tem sido utilizado como referência à condição das sociedades diante do contexto das redes digitais e das tecnologias da informação, aspectos que podem definir a reorganização dos pólos de riqueza.

Um importante documento que pode balizar tais discussões é o The Global Information Technology Report, relatório elaborado pelo World Economic Forum (Fórum Econômico Mundial). O relatório busca promover um rastreamento acerca do uso e da distribuição da tecnologia em 102 países, defendendo a idéia da "crescente influência das tecnologias de informação e da comunicação no desenvolvimento dos países industrializados e de economias emergentes $^{\prime \prime 4}$. De acordo com o relatório, o nível de inclusão digital entre estes países - relativo ao período 2003-2004 — é liderado pelos Estados Unidos, posição mantida há três anos. Em seguida, a lista apresenta Cingapura (segundo), Finlândia (terceiro), Suécia (quarto) e Dinamarca (quinto), aferindo o rápido desenvolvimento da tecnologia da informação nos países nórdicos, além da importante posição ocupada por Cingapura, reflexo das parcerias realizadas por governo e iniciativa privada daquele país no âmbito da TI.

Entre os países asiáticos, além de Cingapura, vale destacar as posições do Japão $\left(12^{\mathrm{a}}\right)$, Taiwan $\left(17^{\mathrm{a}}\right)$, Hong Kong $\left(18^{\mathrm{a}}\right)$, Índia $\left(45^{\mathrm{a}}\right)$ e China $\left(51^{\mathrm{a}}\right)$. No continente africano, a melhor posição é ocupada pela África do Sul, $37^{a}$ no ranking geral, seguida pela Tunísia $\left(40^{\mathrm{a}}\right)$. Já o Brasil ${ }^{5}$ ocupa a $39^{\mathrm{a}}$ colocação - caindo dez posições em relação ao ano anterior - , sendo superado pelo Chile (32 $\left.{ }^{a}\right)$ na América Latina. Apesar do relatório sugerir que a "divisão digital" entre os países desenvolvidos e os mais pobres vem diminuindo a cada aferição anual e que a "tecnologia da informação é uma poderosa ferramenta na luta contra a pobre$\mathrm{za}^{\prime \prime 6}$, o amplo domínio da lista pelos mesmos países industrializados demonstra, certamente, a relação entre concentração de capital e desenvolvimento tecnológico.

Desta maneira, podemos verificar que a tese do Fórum Econômico Mundial é baseada exatamente na idéia de que o crescimento econômico deve ser fomentado pelo investimento, uso e aplicação das tecnologias de informação e comunicação, conforme declara Klaus Schwab (2003), fundador 
e presidente executivo do Fórum. Esta esperança é reforçada pela presença de vários países periféricos na referida lista, o que poderia demonstrar um momentâneo crescimento naquelas regiões.

Por sua vez, a Conferência Mundial da Sociedade da Informação (World Summit on the Information Society), que teve lugar em Genebra, de 10 a 12 de dezembro de 2003, parece sugerir um hiato entre os propósitos do Fórum Econômico Mundial e a realidade dos países mais pobres ou em desenvolvimento, embora também reconheça o potencial das tecnologias de informação e comunicação na promoção do desenvolvimento destes países. A Declaração de Princípios da Conferência ${ }^{7}$, documento resultante dos debates ali travados, reflete a preocupação dos representantes de vários países acerca do acesso às tecnologias de informação e da comunicação, numa visão redentora destas tecnologias. Para eles, a Sociedade da Informação deve se preparar para oportunizar, a todos, os benefícios tecnológicos, bem como o direito de criar, acessar e compartilhar o conhecimento.

Já o plano de ação elaborado pelos participantes da conferência propõe, entre outros aspectos, uma ampliação das redes de comunicação em escala global, buscando estabelecer uma conexão entre cidades, universidades, escolas, hospitais, bibliotecas, entidades governamentais etc. Além disso, o plano requisita que todas as populações do mundo tenham acesso ao rádio e à televisão e que possam produzir seus conteúdos na Internet em seus próprios idiomas, sugerindo, ainda, que as estruturas curriculares das escolas sejam adaptadas aos desafios da Sociedade da Informação ${ }^{8}$. Ou seja, ampliar, de fato, o espectro das tecnologias de informação e da comunicação no seio das sociedades com vistas à inclusão digital.

Contudo, apesar de acreditar que a Internet pode favorecer o desenvolvimento do Terceiro Mundo, Castells (2003, p.215) também observa que "as condições sob as quais a Internet está se difundindo na mai- oria dos países estão criando uma divisão digital mais profunda". Mas seu discurso não é de todo pessimista; antes, para construirmos um cenário diferente, ele propõe uma mudança no contexto da apropriação da Internet, o que poderia gerar uma nova correlação de forças na rede mundial e, por extensão, nas economias nacionais.

Por seu lado, Pierre Lévy (1999) julga improcedentes os juízos a priori acerca da Internet apenas em razão de seus aspectos econômicos, comparando-a com outros meios como o telefone e o cinema enquanto instrumentos de geração de riqueza. Para ele, a exploração econômica da Rede ou a exclusão digital não anulam os benefícios e as particularidades daquela frente aos meios tradicionais:

[...] não vejo por que a exploração econômica da Internet ou o fato de que atualmente nem todos têm acesso a ela constituiriam, por si mesmos, uma condenação da cibercultura ou nos impediriam de pensá-la de qualquer forma que não a crítica (Lévy, 1999, p. 13).

A associação "conveniente" entre os aspectos sociais e empresariais da Internet também foi registrada por Lévy, para quem "não há sentido em opor o comércio de um lado e a dinâmica libertária e comunitária que comandou o crescimento da Internet de outro. Os dois são complementares, para desgosto dos maniqueístas" (Lévy, 1999, p. 13). A assimetria global aferida em torno dos desequilíbrios econômicos e tecnológicos entre os países, portanto, não nos impede de uma análise mais detida sobre os fenômenos da cibercultura, tampouco de fazer uso dos seus dispositivos. Como afirma Flichy (2001, p. 9), os inúmeros aspectos da Internet raramente são estudados de forma simultânea ${ }^{9}$; para tanto, devemos esquadrinhar seus diversos fenômenos de forma integrada. Assim, da indústria informática à desmaterialização da produção e da riqueza, veremos o surgimento de um 
novo modelo econômico que vem caracterizando tanto as relações internacionais quanto as operações entre as empresas, compreendido como a "nova economia".

\section{Economia informacional e $\bullet$ processo de globalização: ๑ ad- vento de uma "nova economia"}

A década de 1980, marcada pela desregulamentação e pela privatização dos serviços públicos em diversos países (Mattelart, 2002a, p. 107), será palco de uma reestruturação do panorama financeiro mundial. Neste período, podemos registrar a difusão das idéias acerca da globalizaçãa ${ }^{10}$, onde os Estados-nações passarão a ocupar uma posição secundária frente aos mercados globais e aos fluxos de capital em nível internacional. Mattelart (2002b, p. 591-612) descreve um sucinto panorama sobre o discurso da globalização, apresentando as noções fundadoras que ora reiteram, ora mitificam o processo de interdependência econômica dos países ${ }^{11}$. Numa análise sistêmica, porém, poderemos verificar que a internacionalização do capital - acentuada com o fim da Guerra Fria em 1989 (com a queda do muro de Berlim e o reposicionamento político dos países socialistas) - irá, de fato, implicar a "internacionalização do processo produtivo” (Ianni, 2002, p. 63).

É desta maneira que podemos citar alguns aspectos importantes que caracterizam o êxito comercial das empresas contemporâneas, lastreado por um processo amplamente denominado de "globalização":

- As facilidades comunicacionais entre os consumidores e as organizações, entre estas e seus fornecedores e filiais;

- O avanço nos sistemas de circulação e transporte de matéria-prima e produtos, fazendo com que as distâncias deixem de ser obstáculos aos novos negócios e mercados;

- A informatização de empresas, bem como o alto nível de automação dos pro- cessos de industrialização;

- A fragmentação da produção e o compartilhamento da mão-de-obra entre países onde a remuneração é mais barata (geralmente, zonas de subemprego ou de alto desemprego), promovendo uma redução no custo final dos produtos.

Entretanto, é na chamada "nova economia" que irão se concentrar as mudanças mais expressivas das categorias econômicas. O termo se refere a um novo modelo de geração de riqueza a partir da revolução tecnológica e da centralidade adquirida pela comunicação nas sociedades contemporâneas. As cadeias produtivas vão se basear em novos procedimentos e aparatos de fabricação e distribuição. O termo "nova economia" também está relacionado às diversas mudanças introduzidas pelo processo de globalização e pelas tecnologias de informação (Hartley, 2002, p. 162), onde aspectos como competências, inteligência e informação recebem especial atenção.

Para Castells (1999, p. 87), a nova economia é, essencialmente, global e informacional. Os vetores de produtividade e competitividade que norteiam a economia tradicional dependem, agora, da capacidade de processamento e aplicação da informação e do conhecimento pelas organizações. A gestão do conhecimento e do capital intelectual das empresas passa a compor o rol das estratégias comerciais. Podemos registrar, também, novas formas de recepção e consumo, produção e distribuição. A concepção de propriedade passa por uma oscilação, uma vez que o próprio produto já não se apresenta de forma tangível e a atribuição de valor atende a outros parâmetros de negociação. A concorrência, antes localizada, transfere-se para um mercado global; entretanto, aquela não se dá apenas entre companhias do mesmo segmento: há um cruzamento de competitividade que ultrapassa fronteiras e produtos, cuja transversalidade pode subsumir, por exemplo, numa mesma disputa, empresas de entretenimento, esportes e cultura.

Apesar de uma base material ter sido 
desenvolvida para viabilizar a comunicação em escala mundial - através de computadores, fibra ótica, satélites etc. - , a revolução reside, exatamente, na superação das estruturas físicas e na desmaterialização dos produtos ou das relações comerciais, aspectos estes favorecidos, sobretudo, pelas tecnologias de informação. Como Lull (2000, p. 213) sugere, a tecnologia da informação vai se desenvolver longe das grandes (e "pesadas") companhias; entretanto, da riqueza gerada pelas novas empresas de TI irão emergir grandes conglomerados de informática. Neste sentido, Kevin Kelly (1999) se refere à nova economia enquanto um elemento baseado nos bens intangíveis, mas que superam as categorias clássicas de riqueza, introduzindo, também, novos modelos de serviços. Para ele,

...a nova economia lida com entidades impalpáveis como a informação, relacionamentos, copyright, entretenimento, títulos e derivativos. [...] O etéreo mundo dos computadores, do entretenimento e das telecomunicações é hoje um setor maior que qualquer dos velhos gigantes de antigamente, tais como a construção civil, os produtos alimentícios ou a indústria automobilística (Kelly, 1999, p. 11)

A compreensão de Kelly acerca dos bens intangíveis é justificada pelo potencial das redes e pelas formas variadas de ofertas de serviços que verificamos atualmente. Ele sugere uma relação intrínseca entre a comunicação, a cultura e a sociedade, onde os efeitos da "tecnologização" transcendem a escala de um mero ciclo industrial (Kelly, 1999, p. 14).

A nova economia também pode ser caracterizada por subversões na ordem econômica ou nos modelos tradicionais de produção e riqueza. $\mathrm{O}$ marketing digital, o comércio eletrônico (também chamado de e-commerce), as empresas que rapidamente surgem e acumulam lucros, e até mesmo um mercado específico de negociação para ações de empresas de tecnologia (da informática à biotecnologia) capitaneado pela Nasdaq ${ }^{12}$, atestam a centralidade da tecnologia nos negócios. As empresas denominadas "ponto com", isto é, organizações comerciais cujo endereço na World Wide Web é definido pela extensão ".com" em sua $U R L^{13}$, personificam a "web economy" - a nova economia em sua versão para o mundo dos negócios on-line, conforme registram Burnett e Marshall (2003, p. 105) ${ }^{14}$. Outro exemplo recente das mudanças das categorias econômicas foi a fusão ocorrida, em janeiro de 2000, entre a companhia America Online (uma empresa pioneira na prestação de serviços de acesso à Internet) e o conglomerado de mídia americano Time Warner, formando o conglemerado de mídia e tecnologia AOL-Time Warner ${ }^{15}$. Desta maneira, se a nova economia é a economia das redes, o comércio eletrônico mundial encontra na Internet sua conexão entre produtores, consumidores e prestadores de serviços (Castells, 2003, p. 65).

As redes globais empresariais - empresas transnacionais cujas culturas organizacionais internalizaram o conceito de rede são diretamente dependentes do processamento automático de informações. Isto não se limita apenas às mensagens diárias trocadas entre funcionários de filiais distantes ou boletins enviados pelas instâncias superiores de uma organização por e-mail ou videoconferência. Trata-se de um processo cujos serviços e produtos são oferecidos no sentido de otimizar rotinas e resultados, onde o fluxo da informação exige imediatismo para a divisão do trabalho.

Presenciamos, então, um redimensionamento das culturas organizacionais e dos próprios modos de produção: organização em torno do processo (e não da tarefa); passagem da burocracia vertical para a hierarquia horizontal; interoperacionalidade e flexibilidade, adaptação e antecipação (Castells, 1999, p. 185). Tais aspectos evocam as características das redes de comunicação e, de uma maneira geral, dos novos media. 


\section{Uma economia dos novos media}

As tecnologias da comunicação e da informação também legaram um novo momento para as sociedades na esfera econômica, conforme relatado anteriormente. Os novos media já são, por si só, a resultante de variáveis históricas, do desenvolvimento tecnológico, mas também da concentração de capital pelas sociedades. Os próprios meios e seus conteúdos definem uma economia particular, com estruturas singulares de organização, produção e difusão. Não será difícil inferir que uma "economia dos novos media" também irá emergir como um elemento dissonante frente às categorias econômicas tradicionais, levando ao limite os parâmetros da nova economia. Aliás, Kelly (1999, p. 13) observa que "a comunicação - que, no final das contas, é o elemento central das atividades da tecnologia e da mídia - não é apenas um setor da economia. A comunicação é a economia".

Para Dizard (2000, p. 35), "a eletrônica está forçando a integração técnica das mídias antiga e nova, com impactos importantes sobre a futura forma e direção da indústria". Esta integração sugere uma capacidade de sinergia entre os meios de comunicação na exploração das novas tecnologias. $\mathrm{O}$ processo cumulativo das tecnologias que desenhou o conjunto dos media atuais também afetou os indivíduos nas suas formas de assimilação dos meios digitais, pois passamos de um modelo fundado nos mass media para estruturas personalizadas de produção e difusão da informação. Esta migração rumo ao meio digital não repercutiu apenas nos aspectos técnicos, econômicos e sociais; as próprias análises ainda se ressentem da novidade, como observa Vilches:

Como era de se esperar, a nova realidade do mercado mundial e a aceleração das inovações na denominada Sociedade da Informação pegaram de surpresa o mundo das teorias da comunicação. [...] O certo é que a maio- ria das teorias pertencentes à tradição da pesquisa em comunicação encontra-se defasada para oferecer respostas conceituais frente à emergência dos novos meios [...] (Vilches, 2003, p. 182).

Os estudos tradicionais da economia política da comunicação, geralmente, descrevem o arco de funcionamento dos meios a partir da propriedade destes meios até as implicações dos seus conteúdos, através de categorias econômicas e normatizadoras. Entretanto, como se aproximar destes aspectos num ambiente digital onde a circulação de produtos é substituída por processos imediatos de distribuição e o consumo se dá, em boa medida, através de produtos como programas de computador, músicas ou imagens? Se, na virada do ano 2000, a indústria e a mídia, como um todo, apostavam no formato do disco digital como um suporte unificador (CD, CD-rom, DVD etc.) - como observa Dizard Jr. (2000, p. 62) veremos, por outro lado, que boa parte dos seus conteúdos (respectivamente, músicas, dados e material audiovisual) já flui significativamente pelas redes de comunicação de maneira a prescindir destes dispositivos físicos.

O compartilhamento de arquivos (através da tecnologia peer-to-peer, isto é, ponto a ponto) pela Internet irá demonstrar, por exemplo, a desmaterialização (ou, neste caso, a virtualização) destes processos e uma série de rupturas nas cadeias de produção daqueles bens culturais. A "economia digital" vai redefinir, então, a condição dos bens culturais, como assinala Fontenay (2000). O tráfego de músicas, textos, filmes, pacotes de dados e programas pela Rede está redesenhando tanto as relações econômicas como as formas de produção da cultura e do entretenimento na sociedade contemporânea.

A inscrição no mundo digital depende, portanto, de aspectos econômicos e socioculturais, do domínio dos recursos e equipamentos. Integrar-se ao meio digital 
irá pressupor, também, uma ampla capacidade de assimilação, seleção e processamento da informação e do conhecimento pelos indivíduos e grupos sociais. As variantes e os desequilíbrios econômicos da sociedade tecnológica parecem confinar o empreendimento da Sociedade Global da Informação - a sociedade do conhecimento, baseada na relação do todos-para-todos a um universalismo anódino, sem aderência a um projeto mais amplo de superação das disparidades entre os países. Contudo, a geopolítica do mundo digital também desequilibra os centros de poder e propriedade, ainda que tenhamos uma nova forma de concentração destes elementos na grande Rede. Assim, a migração digital, longe de ser um projeto totalizante, esboça, de forma paritária, a integração sociocultural e a individualização, num processo de interdependência tecnológica que pode atenuar a assimetria em questão •

\section{Notas}

10 termo "pós-industrial" foi cunhado em 1913 pelo indiano Ananda K. Coomaraswamy, que idealizava uma sociedade onde a diversidade cultural e a descentralização iriam inibir a uniformização de um sistema mecânico industrial. Ver: Mattelart (2002a, p. 52). Para nosso trabalho, evitamos 0 adensamento da polêmica em torno da noção de "sociedade pós-industrial": embora isto não signifique uma filiação intempestiva à corrente de pensamento em questão, assumimos a pertinência do seu uso por reconhecê-la mais inclusiva e mais explicativa numa análise do ponto de vista cronológico.

2 Ver: Touraine (1973).

3 Nesta obra, Bell analisa a forma pela qual as economias mais avançadas, como EUA e Japão, estão passando da geração de produtos para serviços e processamento da informação. Ver: Bell (1999).

4 Conforme apresentação do relatório Global Information Technology Report 2003-2004, disponível em $<$ www.weforum.org> 09.12.03 (11.12.03).
5 A respeito dos aspectos relacionados às tecnologias da informação no Brasil, sugiro a leitura do documento Sociedade da Informação no Brasil: livro verde, organizado por Tadao Takahashi (2000), onde também são apresentadas propostas de inclusão digital para o país. A organização do livro foi uma das estratégias do Programa Sociedade da Informação (SOCINFO), criado pelo Decreto Presidencial 3.294, de 15 de dezembro de 1999.

6 Conforme Information and Communication Technology is a powerful tool in the fight against poverty, disponivel em $<$ www.weforum.org > (09.12.03). (11.12.03).

7 Conforme Declaration of Priciples. Building the Information Society: a global challenge in the new Millennium, disponível em <www.itu.int/wsis/documents/index.html> (20.12.03).

8 Conforme Plan of Action, disponível em <www.itu.int/ wsis/documents/index.html (20.12.03).

9 Daí o seu empreendimento no sentido de estudar, de forma detalhada, o "espírito da Internet", numa alusão ao trabatho de Max Weber (1989). Ver: Flichy (2001, p.10).

10 Para uma análise do processo de globalização, ver Ianni (2002).

11 Mattelart (2002b, p. 593) vai lembrar que a noção de "interdependência", que parece uma criação recente, data, na verdade, do final do século XIX.

12 Sigla em inglês para National Association Securities Dealers Automated Quotation. A Nasdaq foi criada em 1971, sendo 0 primeiro mercado acionário eletrônico do mundo, podendo, atualmente, ser acessada de qualquer lugar, 24 horas por dia, para a realização de negócios. Ver: $<$ www.nasdaq.com/about/about_nasdaq.stm). (10.12.02)

13 Sigla para Uniform Resource Locator, isto é, Localizador Uniforme de Recursos. São os endereços utilizados para a localização de páginas na Internet através da sintaxe Universal Resource Identifier (Identificador Universal de Recursos).

14 Algumas empresas on-line podem ilustrar a natureza deste segmento: Amazon (<www.amazon.com>), Ebay (<www.ebay.com>), Mp3.com (<www.mp3.com>), Real Networks (<www.real.com $\rangle)$ etc. Burnett e Marshall (2003, p.119) também registram dois aspectos relacionados ao desenvolvimento da "Web economy": num primeiro 
nível, as transações business-to-business (B2B Internet); num segundo, as transações business-to-consumer (B2C).

15 A respeito da fusão entre estas companhias, ver Aufderheide (2002).

\section{Referências}

AUFDERHEIDE, Patricia. Competition and commons: the public interest in and after the Aol-Time Warner merger. Journal of Broadcasting \& Electronic Media. $\mathrm{N}^{0}$ 46, v.4, 2002, p. 515-531.

BELL, Daniel. The coming of post-industrial society: a venture in social forecasting. New York: Basic Books, 1999.

BRETON, Philippe e PROULX, Serge. Sociologia da comunicação. São Paulo: Edições Loyola, 2002.

BURNETT, Robert; MARSHALL, David P. Web theory: an introduction. London: Routledge, 2003.

CASTELLS, Manuel. A sociedade em rede. São Paulo: Paz e Terra, 1999.

- A galáxia da internet: reflexões sobre a internet, os negócios e a sociedade. Rio de Janeiro: Jorge Zahar Ed., 2003.

DIIZARD JR., Wilson. A nova mídia: a comunicação de massa na era da informação. Rio de Janeiro: Jorge Zahar Ed., 2000.

FLICHY, Patrice. L'imaginaire d'internet. Paris: Éditions La Découverte, 2001.

FONTENAY, Eric. The digital economy: how digital goods are reshaping the rules of commerce. < http://www.musicdish.com/mag/ index.php3?id=2109>, 01.11.2000. Acesso em: 19.04.2003.

HARTLEY, John. Communication, cultural and media studies: the key concepts. London: Routledge, 2002.

IANNI, Octavio. Teorias da globalização. Rio de Janeiro: Civilização Brasileira, 2002.

KELLY, Kevin. Novas regras para uma nova economia. Rio de Janeiro: Editora Objetiva, 1999.

LÉVY, Pierre. Cibercultura. São Paulo: Ed. 34, 1999.

LULL, James. Media, communication, culture: a global approach. New
York: Columbia University Press, 2000.

LYOTARD, Jean-François. O pós-moderno. Rio de Janeiro: José Olympio, 1986.

MATTELART, Armand (a). História da sociedade da informação. São Paulo: Loyola, 2002.

(b). An archaelogy of the global era: constructing a belief. Media, Culture \& Society. London: Sage Publications, 2002. Vol. 24, p. 591-612.

MIÈGE, Bernard. 0 pensamento comunicacional. Petrópolis: Vozes, 2000.

SCHWAB, Klaus. Global Information Technology Report shows IT becoming a "Powerful Tool in the Fight Against Poverty" in developing countries. In: World Economic Forum. <www.weforum.org>, 09.12.03. Acesso em: 11.12.03.

TAKAHASHI, Tadao (org.). Sociedade da informação no Brasil: livro verde. Brasília: Ministério da Ciência e Tecnologia, 2000.

TOURAINE, Alain. La société postindustrielle: naissance d'une société. Paris: Editions Denoel, 1973.

VILCHES, Lorenzo. A migração digital. São Paulo: Edições Loyola/Editora Puc-Rio, 2003.

WEBER, Max. A ética protestante e o espírito do capitalismo. São Paulo: Pioneira, 1989.

WORLD ECONOMIC FORUM. Global Information Technology Report 2003-2004. Disponível em: <www.weforum.org>, 09.12.03. Acesso em 11.12.03.

WORLD SUMMIT ON THE INFORMATION SOCIETY. Declaration of Priciples. Building the Information Society: a global challenge in the new Millennium. Disponível em: <www.itu.int/wsis/ documents/index.html>, 12.12.03. Acesso em: 20.12.03. 